\title{
THe EFfect of Lower Limb Passive MOVEMENT ON LUNG FUNCTION
}

\begin{abstract}
This study examined the effects of ankle passive movement on lung function in healthy adults. A pre-test post-test experimental design was used. Passive plantar and dorsiflexion of the ankle were performed at 60 repetitions per minute on 60 healthy subjects in the supine position. Lung function at rest was compared to that during passive movements. The results indicated that all measured parameters including the breathing frequency, tidal volume, minute ventilation, oxygen consumption and

NARAIN S', LIN J², PUCKREE T3;

1 Addington Hospital, Kwa-Zulu Natal, South Africa

2 Deparment of Biochemistry and Microbiology, University of Zululand, Private Bag X1001, Kwa Dlangezwa 3886, South Africa

3 Department of Physiotherapy, University of Durban-Westville, South Africa carbon dioxide output, increased significantly during passive movements as compared to those at rest. The authors conclude that passive movements elicit a significant ventilatory increase in healthy human subjects. The effect of passive movements in the treatment of unconscious or diseased individuals should be investigated.
\end{abstract}

\section{KEY WORDS: PASSIVE MOVEMENT, MINUTE VENTILATION, CUTANEOUS STIMULATION, BREATHING FREQUENCY, TIDAL VOLUME.}

\section{INTRODUCTION}

Passive movements are commonly used by physiotherapists to improve or maintain the circulation in paralysed conscious or unconscious patients (Kisner and Colby, 1990a). The range of motion of the joints and length of soft structures are also maintained or increased through the use of this technique. Anecdotal information relating to the effects of passive movements as described above is readily available and well known. However the effects of passive movements in enhancing lung function in either conscious or unconscious patients is not known.

The effects of active exercise on lung function have been well documented (Comroe et al, 1943; Dejours et al, 1959; Ishida et al, 1993 and Jensen, 1972). Jensen (1972) showed that within 20 seconds of voluntary exercise, the transient ventilatory responses during arm work were greater than those during legwork. Other researchers (Davies and Sargeant, 1974; Sawka, 1986 and Celli et al, 1988) reported that the accessory inspiratory muscles became activated when the upper torso and arm were positioned during the unsupported arm exercise and caused a change in ventilation.

Gozal (1996) demonstrated that lower limb motion induced by passive backward pedaling elicited a significant and sustained ventilatory increase in healthy children. Furthermore upper body motion associated with rhythmic swaying of the lower extremities has been implicated in the ventilatory response to exercise. Ishida et al (1993) also reported an increase in the minute ventilation of humans at the onset of passive leg movements during sleep. Hajek and Mader (1990) found that oxygen consumption was increased during active movements, yet it was reduced during passive movements.

The effects of physiotherapeutic passive movements on lung function have not been systematically investigated. The purpose of the present study was to determine the effects of passive movements on selected lung function variables.

\section{METHODS}

This study was approved by the Ethics Committee of the University of DurbanWestville. Sixty healthy non-smoking male and female volunteers from the University campus participated by voluntary informed consent. Subjects had no history of cardiopulmonary or neuromuscular disease, and sensation over the joints (proprioception and cutaneous) where passive movements were applied was intact. Each subject was told about the experimental procedure in detail but was not acquainted with the purpose of the experiment.

\section{Meosurements}

Tidal volume $\left(\mathrm{V}_{\mathrm{t}}\right)$, breathing frequency $\left(\mathrm{F}_{\mathrm{b}}\right)$, minute ventilation $\left(\mathrm{V}_{\mathrm{e}}\right)$, oxygen consumption $\left(\mathrm{V}_{2}\right)$ and carbon dioxide $\left(\mathrm{VCO}_{2}\right)$ output were measured using the MetaMax mask and volume transducer Triple-V® (Cortex MetaMax, Portable Test System; Biophysik GmgH - Model SBS). A Nation ${ }^{\circledR}$ tube was used to guarantee a constant humidity during measurements. The pneumotachometer was calibrated using a 3-litre calibration syringe. All data was stored on the Cortex MetaMax logger and analyzed on computer.

\section{Procedure}

Each subject was allowed to rest in supine for 2 minutes before the actual main experiment was performed. The Cortex Metamax mask was applied. The pulmonary variables were monitored for 2 minutes at rest and for 2 minutes with the researcher's hands placed on the right foot (cutaneous stimulation).

\section{CORRESPONDENCE TO:}

Dr. T. Puckree

Department of Physiotherapy University of Durban-Westville

Private Bag X 54001

South Africa

Tel: 27-31-2044817

Emai]: lpuckree@pixie.udw.ac.za 
Passive plantar and dorsiflexion of the right ankle joint (Kisner and Colby, 1990b) were performed in supine lying subjects for 2 minutes at $60 \mathrm{rpm}$. Subjects were instructed to relax and not to resist the motion or actively participate in it. Care was taken to support the body as much as possible to avoid voluntary contractions and motion artifacts. In addition traction or compression was not applied either on the tendoAchilles or the ankle joint. All movements commenced with dorsiflexion. In order to minimize error passive movements were applied to all subjects by the same investigator.

The Cortex Metamax automatically saved data in the logger for every 10 seconds.

\section{Data Analysis}

The data was transferred from the Metamax logger onto a computer. The analogue data of each variable for each subject were then reduced to a quantitative form using the Cortex Metamax software. Mean and standard deviation of the quantified data were calculated. Statistical comparisons were applied using the paired t-test. The probability was set at 0.05 .

\section{RESULTS}

Sixty healthy subjects, 19 male and 41 female subjects, aged 18 to 30 years; height $152-179 \mathrm{~cm}$; body mass, $45-80 \mathrm{~kg}$, participated in this study. The data from all subjects were considered usable. None of the measured parameters showed any significant difference across gender.

Figure 1 shows a significant increase $(28,7 \%)$ in breathing frequency from rest to when the passive movements were applied. Response to the cutaneous stimulation was also significantly different from those at rest $(14,5 \%)$. There was no significant difference between the responses to the cutaneous stimulation and when the passive movements were applied.

As shown in Figures 2 and 3, both tidal volume $\left(\mathrm{V}_{\mathrm{t}}\right)$ and minute ventilation $\left(V_{e}\right)$ showed significant increases during the cutaneous stimulation $(15,0 \%$ and $17,2 \%$ respectively) and during passive movement $(20,5 \%$ and $34,7 \%$ respectively) as compared to rest. Responses

FIGURE 1. Mean and standard deviation of breathing frequency at rest, during cutaneous stimulation and passive movements $(n=60),{ }^{*}$ indicates significant difference $(p<0.05)$ compared to rest.

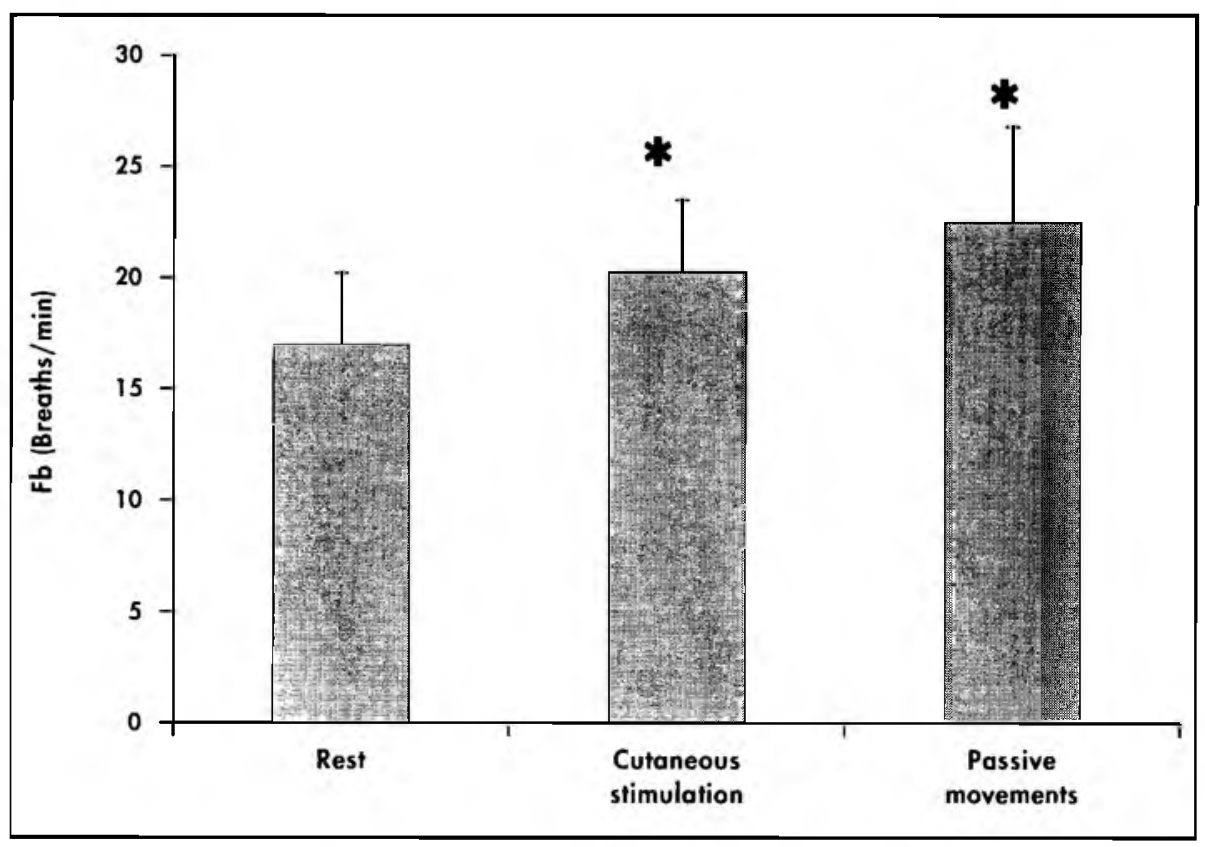

FIGURE 2. Mean and standard deviation of tidal volume at rest, during cutaneous stimulation and passive movements $(n=60),{ }^{*}$ indicates significant difference $(p<0.05$ ) compared to rest. \# Indicates significant difference $(p<0.05)$ compared to cutaneous stimulation.

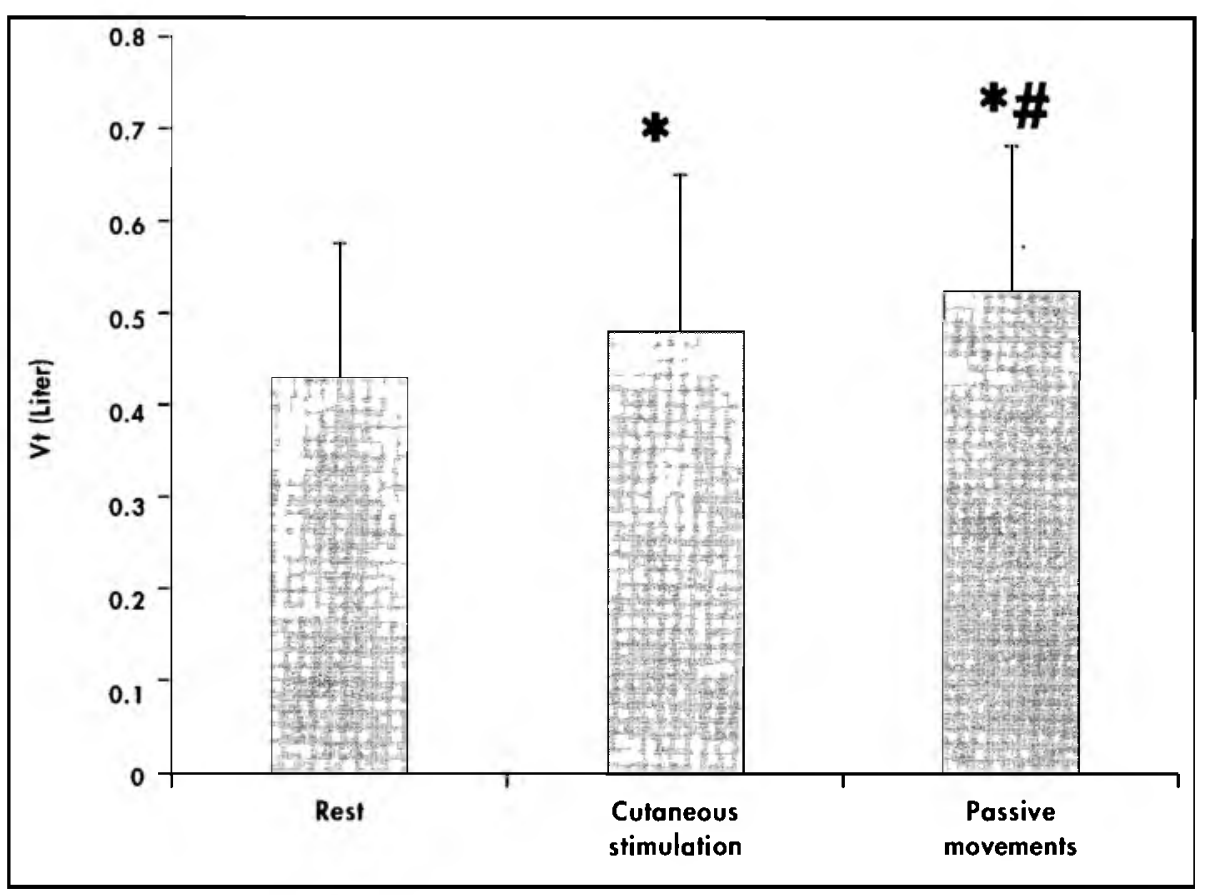

to the cutaneous stimulation were also significantly different compared to that during passive movement.

Both $\mathrm{O}_{2}$ consumption and $\mathrm{CO}_{2}$ output were significantly increased by both passive movements $(10,5 \%$ and $29,3 \%$ respectively) and the cutaneous stimulation (9,3\% and $18,5 \%$ respectively) as compared to rest (Figures 4 and 5). There was a significant difference in $\mathrm{CO}_{2}$ output but not in $\mathrm{O}_{2}$ consumption during passive movement as compared to the cutaneous stimulation.

\section{DISCUSSION:}

In the present study the authors attempted to compare the changes in lung function at rest to those during the cutaneous 
FIGURE 3. Mean and standard deviation of Minute Ventilation at rest, during cutaneous stimulation and passive movements $(n=60),{ }^{*}$ indicates significant difference $(p<0.05)$ compared to rest. \# Indicates significant difference $(p<0.05)$ compared to cutaneous stimulation.

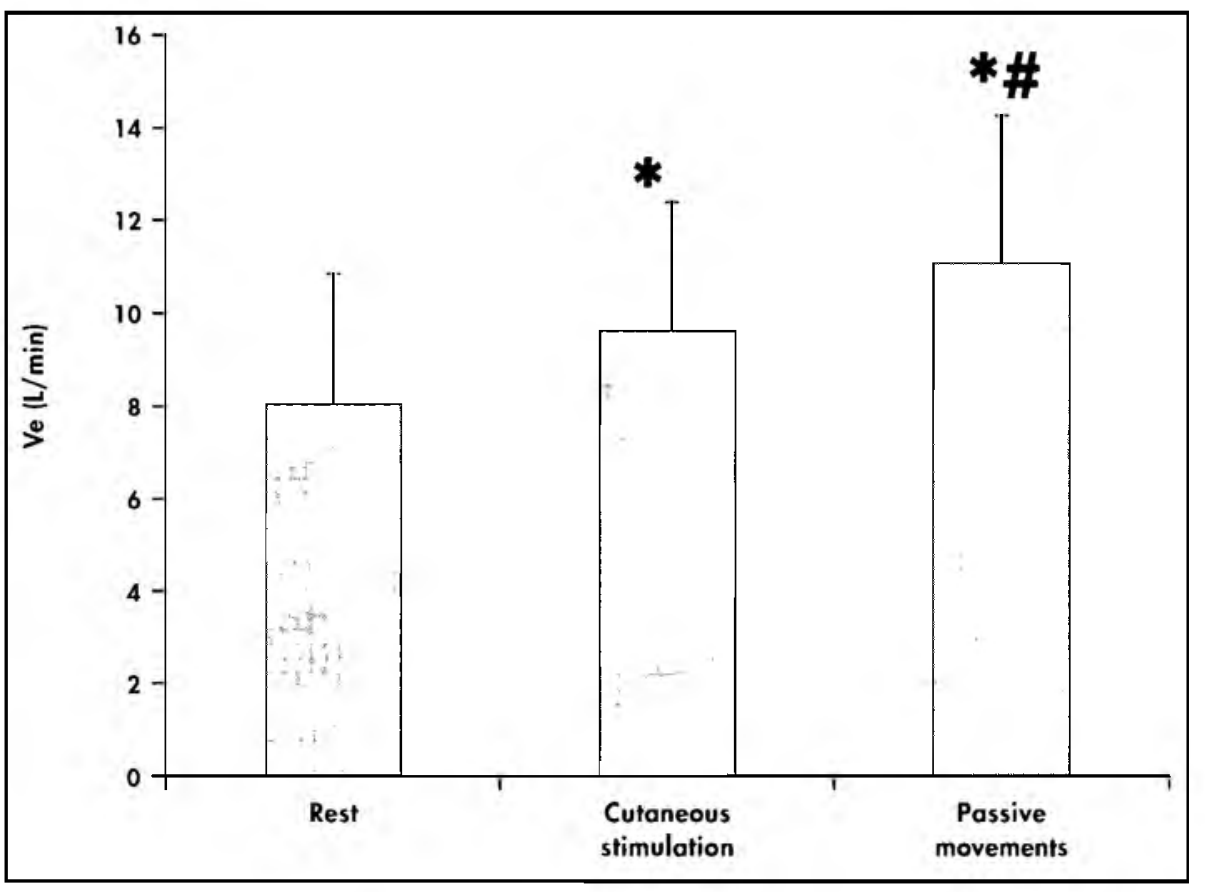

FIGURE 4. Mean and standard deviation of Oxygen Consumption at rest, during cutaneous stimulation and passive movements $(n=60),{ }^{*}$ indicates significant difference $(p<0.05)$ compared to rest.

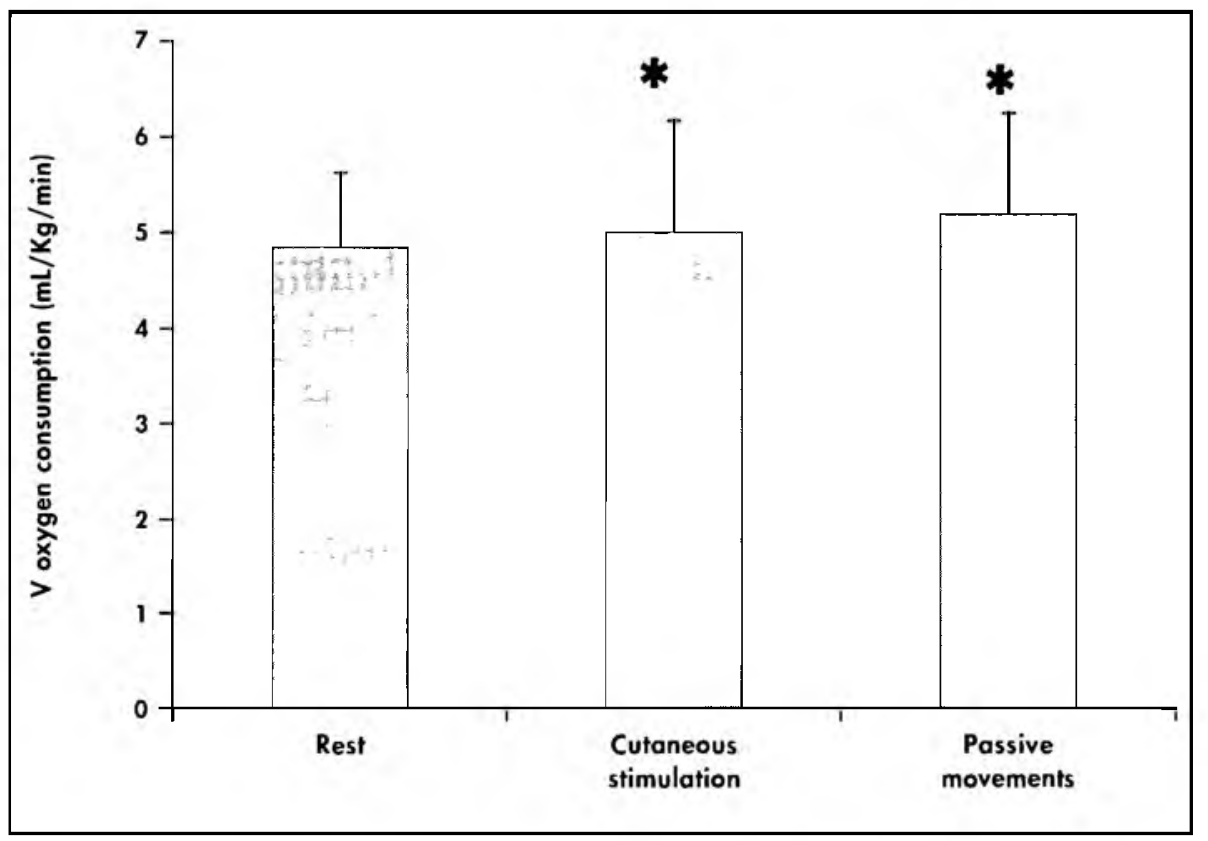

stimulation and passive movement of the ankle. Breathing frequency $\left(\mathrm{Fb}_{b}\right)$, tidal volume $\left(\mathrm{V}_{\mathrm{t}}\right)$, minute ventilation $\left(\mathrm{V}_{\mathrm{e}}\right)$, oxygen consumption and $\mathrm{CO}_{2}$ outputs increased significantly during passive movements as well as the cutaneous stimulation compared to the rest phase, with no significant difference in the above pulmonary variables among different genders. Although both cutaneous stimulation and passive movements increased all measured pulmonary variables, there were significant differences (increases) in $\mathrm{V}_{\mathrm{t}}, \mathrm{V}_{\mathrm{e}}$ and $\mathrm{CO}_{2}$ outputs during the passive movements compared to cutaneous stimulation.

The findings of this study are in accordance with those of previous inves- tigations (Waisbren el al, 1990; Ishida et al, 1993)). Waisbren et al, (1990) suggested that a rapid increase in ventilation at the onset of passive movement is a true hyperventilation and that stimulation of the joints can be a significant contributor. Ishida et al (1993) also found an increase in ventilation at the onset of passive movement during sleep and the activity of the cerebral cortex decreased more during wakefulness. These results suggested the existence of neural inhibition from the higher centers to the respiratory center during wakefulness. It is possible that the respiratory center is stimulated by afferent inputs from moving limbs and simultaneously modified by inhibitory and/or facilitatory signals from higher centers so that ventilation might increase at the start of locomotion/ passive movements. Afferent drive from moving limbs could also produce increases in ventilation without any change in cardiac output.

Increased ventilation accompanies motion in animals (Comroe et al, 1943) and humans (Dejours el al, 1959; Jaeger-Denavit el al, 1973). These observations led to a theory that the early reflex hyperpnea of exercise, which originates in the contracting muscle and/or surrounding supportive tissues, is either totally or predominantly mediated by a neural mechanism that affects the respiratory control centers via spinal afferent pathways (Comroe el al, 1959; Flandrois et al, 1967; Harrison et al, 1932). If passive movements facilitate afferent inputs to the respiratory control centers as suggested by previous investigators it is likely that the ventilatory responses observed during passive movements of even a single joint in this study closely approaches the reflex hyperpnea that occurs during the onset of active exercise.

Passive movements of the lower limbs preferentially involve mechanoreceptor feedback mechanisms without activation of feed-forward centers (Eldridge et al, 1991; Waldrop et al, 1989; Gozal et al, 1996). These observations suggest that peripheral afferent pathways activated by passive motion alone, that is, with no feed-forward input and minimal metabolic increases, would be associated with significant ventilatory 
FIGURE 5. Mean and standard deviation of Carbon-di-oxide output at rest, during cutaneous stimulation and passive movements $(n=60)$, " indicates significant difference ( $p<0.05)$ compared to rest. \# Indicates significant difference $(p<0.05)$ compared to cutaneous stimulation.

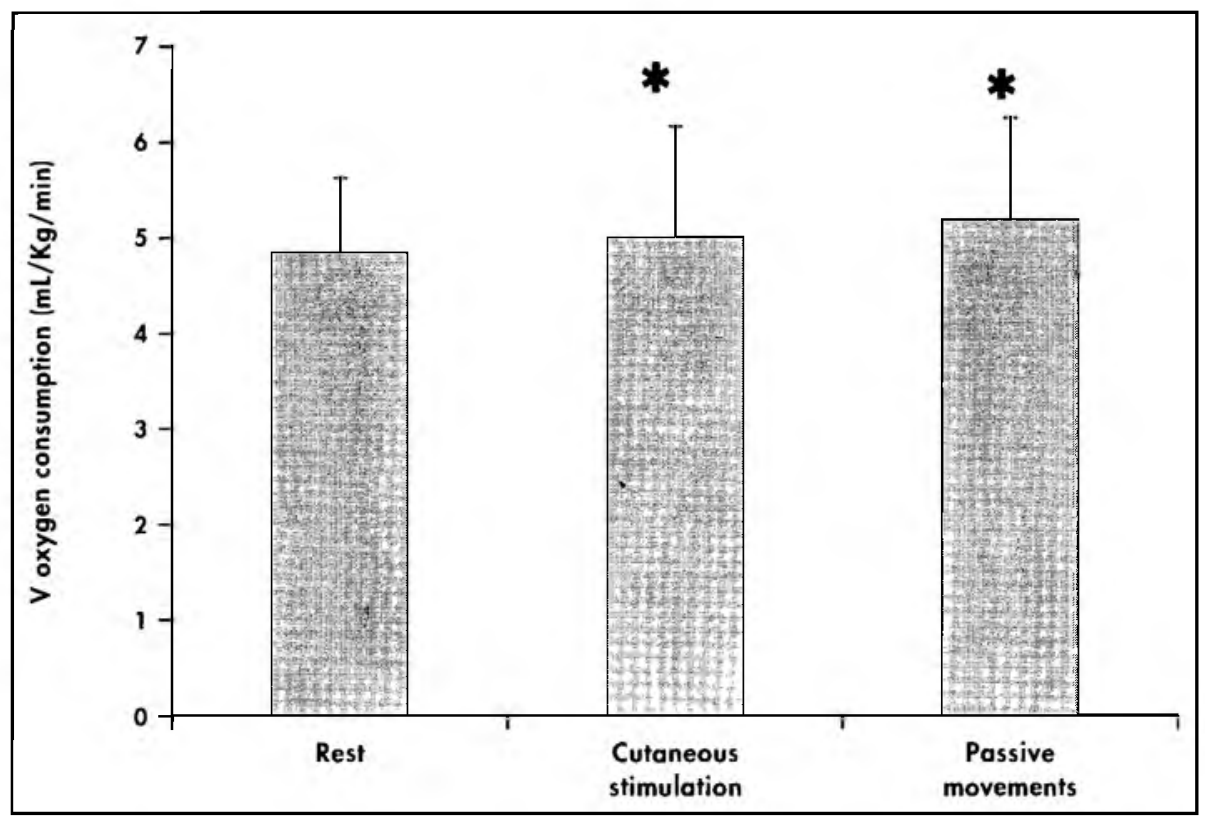

responses by eliciting the activation of mechanoreceptors in the lower limbs.

Brice et al (1988) elucidated the essential role of peripheral neural feedback mechanisms in motion-induced ventilatory increases. Passive movements of lower extremities in humans with clinically complete spinal lesions did not elicit increases in minute ventilation. In the present study all subjects had intact cutaneous and proprioceptive sensations. The finding of a significant increase in all ventilatory parameters from rest to cutaneous stimulations confirms the significance of peripheral neural feedback from cutaneous and static joint receptors. The significant increases in just $\mathrm{V}_{\mathrm{t}}, \mathrm{V}_{\mathrm{e}}$ and $\mathrm{VCO}_{2}$ during passive movements compared to cutaneous stimulation could be attributed to additional input from dynamic joint proprioceptors during the movement. The observed responses in conscious subjects may be due to activation of mechanoreceptors (feedback) and to central command (feed-forward).

This study focussed on the effects of relaxed passive movements of the ankle only on healthy young, conscious subjects. Therefore the results cannot be extrapolated to patients. However the results can serve as a comparison for future studies on a wide range of normal and patient populations for example

geriatrics, postoperative patients, unconscious patients, hemiplegic patients and patients with chronic chest diseases.

In summary passive movements of the ankle in healthy subjects elicit a significant increase in $\mathrm{F}_{\mathrm{b}}, \mathrm{V}_{\mathrm{t}}, \mathrm{V}_{\mathrm{e}}, \mathrm{O}_{2}$ consumption as well as $\mathrm{CO}_{2}$ output. The passive-movement effects were observed at a passive movement frequency of 60 rpm in awake humans. These findings could have value during the use of passive movements to elicit a significant ventilatory increase in conscious subjects. The effects of therapeutic passive movements of other joints and combination of joints in normal and diseased or injured persons needs further investigation.

\section{REFERENCES:}

Brice AGM, Forster HV, Pan LG, Funahashi A, Laury TF, Murphy CL, and Hoffmann MD 1988 Ventilatory and $\mathrm{PaCO} 2$ responses to voluntary and electrically induced leg exercise. J of Applied Physiol $64: 218-225$

Celli B, Criner G, and Rassulo J, 1988 Ventilatory muscle recruitment during unsupported arm exercise in normal subjects $\mathbf{J}$ of Applied Physiol 64: 1936-1941

Comroe JH and Schmidt CF 1943 Reflexes from the limbs as a factor in the hyperpnea of muscular exercise. Am. J. of Physiology 138: $536-547$
Dejours PLY and Teillac A 1959 E'tude du stimulus ventlatoire proprioceptif mis en jeu l'activite motrice chezl'Homme. CR Acad. Sci. (Paris) 248: 2129-2131

Davies CTM and Sargeant AJ 1974 Physiological response to standardized arm work. Ergonomics 17: 41-49

Eldridge FL and Waldrop TG 1991 Neural control of breathing during exercise. In.: BJ Whipp and Wasserman $\mathrm{K}$ ed. Exercise: Pulmonary and Pathophysiology, vol. 52. Lung Biology in Health and disease, Ppl 309370. Marcel Dekker, New York.

Flandrois R, Lancour JR, Islas-Maroquin J and Charlot J 1967 Limb mechanoreceptors including the reflex hyperpnea of exercise. Respr.Physiol 2: 335-343

Gozal D, Marcus CL, Ward D, Keens GT 1996 Ventilatory responses to passive leg motion in children with congenital central hypoventilation syndrome. American J. of Resp. Critical Care Medicine 53: 761-768

Hajek J, Mader T 1990 Pulmonary ventilation and $\mathrm{O} 2$ consumption during passive and active motions in man. Bratisl Lek Listy 91: 94-99
Harrison TR, Harrison WG, Calhoun JA, and Marsh JP 1932 Congestive heart failure. XVIII. The mechanism of dyspnea on exertion. Arch Intern Med 50: 690-720

Ishida K, Yasuda Y and Miyamura M 1993 Cardiorespiratory response at the onset of passive leg movements during sleep in humans. Europ.J. Of Applied Physiol 66: 507-513

Jaeger-Denavit $O$, Lacert $P$ and Grossiord A 1973 Study of ventilatory response to passive movement of the legs in paraplegics. Bull.Pathol.Physiol.Respir 9: 709-710

Jensen I J 1972 Neural ventilatory drive during arm and leg exercise. Scand. J. Clinical Lab. Investig 29: 177-184

Kisner C and Colby LA 1990a Therapeutic Exercise: Foundations and Techniques, 2nd ed., Ppl20-2l, F. A. Davis Company, Philadephia.

Kisner C and Colby LA 1990b Therapeutic Exercise: Foundations and Techniques 2nd ed. Ppl 37-38, F. A. Davis Company, Philadephia.

Sawka MN 1986 Physiology of upper-body exercise. In : K.B. Pandolf ed, Exercise and Sports Science Reviews, vol.14, ppl175-211, Macmillan Publishing Co., New York.

Waisbren SJ, Whiting CS, Nadel ER 1990 Effects of passive limb movement on pulmonary ventilation. Yale J. Biol. Med 63(6): 549-555

Waldrop TG, and Stremel RW 1989 Muscular contraction stimulates posterior hypothalamus neurons. Am. J. Physiology 256: R348-R356 